\title{
DESAFIOS DA PRODUÇÃo AGRÍCOLA CAMPONESA NOS ASSENTAMENTOS DE REFORMA AGRÁRIA Assentamento Milton Santos - Americana/SP
}

\author{
Larissa Mies Bombardi* \\ Sidneide Manfredini** \\ Gabriel de Andrade Fernandez***
}

\section{RESUMO}

Este artigo aborda a Experiência de Extensão em Geografia Agrária coordenada pelas Profạs Drạs Larissa Mies Bombardi e Sidneide Manfredini, e realizada em conjunto com um grupo de alunos do Depto. de Geografia da USP. Tem como finalidade colaborar com as práticas agrícolas e a comercialização que se iniciam no Assentamento Milton Santos localizado nos municípios de Americana e Cosmopólis - São Paulo. Este assentamento apresenta peculiaridades que se colocam como um grande desafio a sua efetiva implantação. Concebido nos moldes de Comuna da Terra, é constituído em sua quase totalidade por famílias de origem urbana, está localizado em uma região monocultora de cana-de-açúcar e dista cerca de $10 \mathrm{~km}$ das áreas urbanas dos municípios aos quais está afeto (Americana, Cosmópolis e Paulínia). À medida que se conseguiu agregar competências diversas ao grupo inicialmente constituído exclusivamente por geógrafos, com alunos e professores da Escola Superior de Agricultura Luiz de Queiroz, da Engenharia Sanitária da Escola Politécnica e da Faculdade de Arquitetura da USP, o projeto foi se ampliando e redirecionando seus objetivos iniciais.

A implementação de sistemas agrícolas otimizados, que condicionariam a efetiva implantação do assentamento, torna imprescindível o resgate da cultura camponesa, essencialmente nos elementos que concorrem para a apreensão e apropriação da paisagem, tanto quanto dos conhecimentos científicos embutidos nas tecnologias a serem empregadas, ou dos limites impostos pela legislação que regem o licenciamento ambiental dos projetos de reforma agrária. As ações deste grupo de trabalho passaram a se dar no sentido da intermediação na apropriação destes conhecimentos, numa perspectiva de gestão participativa que venha a concorrer para a estruturação da tessitura social deste coletivo, levando os assentados a se perceberem como sujeitos no processo de produção deste novo espaço.

PALAVRAS-CHAVE: Extensão, Reforma Agrária, Plano de Assentamento

\section{SUMMARY}

This article discusses the experience of extension in Agricultural Geography coordinated by Prof. Drs. Larissa Mies Bombardi and Sidneide Manfredini, together with a group of students of the Department of Geography at USP. This work aims at supporting agricultural practices and trading, beginning in Milton Santos settlement located between the cities of Americana and Cosmopolis - Sao Paulo. This settlement has singularities that impose as challenges to its effective deployment: Designed in the molds of Comuna da Terra, it is composed almost entirely by families of urban origins, it is located in a region specialized in sugar cane monoculture and it is located about $10 \mathrm{~km}$ from the urban areas of municipalities that affect it (Americana, Cosmópolis e Paulínia). As they managed to add different skills to the group initially consisting solely of geographers, with students and teachers of Escola Superior de Agronomia Luiz de Queiroz, of the Sanitary Engineering at Escola Politécnica and the Faculdade de Arquitetura da USP, the project was widening and redirecting its initial objectives.

The implementation of optimal farming systems, which constrain the effective implementation of the settlement, necessitates the recovery of peasant culture, especially over the factors which contribute to seizure and appropriation of the landscape as far as scientific knowledge embedded in technology to be employed, or limits imposed by the legislation concerning the environmental licensing of agrarian reform projects. The actions of this working group began swifting towards brokering the appropriation of such knowledge, a view of participatory management that will contribute to the structuring of the social fabric of the collective, leading the settlers to acknowledge themselves as the subjects in the production of this new space.

KEY WORDS: Extension, agrarian reform projects, implementation plan 


\section{Apresentação}

O projeto de extensão ora apresentado surgiu a partir da disciplina "Trabalho de Campo em Geografia I", ministrada pela Profa Dra Larissa Mies Bombardi no Departamento de Geografia da Universidade de São Paulo. O trabalho de campo realizado no Assentamento Milton Santos é uma das atividades da referida disciplina e, no ano de 2007, os alunos permaneceram três dias no assentamento, sendo recebidos em duplas pelas famílias assentadas. No retorno ao campo, requisito da disciplina, os alunos apresentaram uma devolutiva para os assentados e, a partir daí, ou seja, a partir do vínculo criado com os assentados e também, a partir das necessidades apontadas pelos próprios assentados no sentido de sua formação com relação às formas de produção, manejo e comercialização, abriu-se espaço para que se gestasse o projeto de extensão em curso.

No mesmo ano, a Pró-reitoria de Graduação da Universidade de São Paulo abriu uma modalidade de bolsa chamada "Ensinar com Pesquisa" que tem como finalidade principal permitir que os alunos desenvolvam habilidades específicas da pesquisa e, ao mesmo tempo, possam eles próprios ensinar. Neste âmbito, foram solicitadas bolsas pela Profa Dra Larissa Mies Bombardi. A partir daí, pôde-se dar início ao trabalho. Atualmente dez alunos envolvidos no Projeto de Extensão são bolsistas do Programa Ensinar com Pesquisa, os demais, tomam parte no trabalho em caráter voluntário, dentre eles, quatro alunos da Engenharia Sanitária da Escola Politécnica e oito alunos da Faculdade de Arquitetura e Urbanismo (FAU). Além dos trabalhos realizados coletivamente por estes alunos, encontram-se em andamento três projetos de trabalho de conclusão de curso e três projetos de mestrado. Além disso, a dinâmica do projeto tem possibilitado participações pontuais, como no caso de duas alunas da Faculdade de Nutrição da USP, que fizeram um levantamento dos hábitos alimentares e doenças a eles relacionadas, ao longo de uma estadia de uma semana.
Constituído a partir de uma nova proposta de assentamento pelo MST, o Assentamento Milton Santos insere-se nessa nova forma chamada Comuna da Terra (SALIN, 2007), que prevê participação de sujeitos sociais que viveram muitos anos em centros urbanos e que possuem um passado recente distante da vida no campo e das práticas camponesas. Além disso, deveriam ter as práticas de agroecologia e vivências de cooperação, como bases fundamentais e essenciais para nortearem a produção.

Situado na bacia do córrego Jacutinga, entre os municípios de Americana e Cosmópolis, o assentamento Milton Santos foi oficialmente iniciado em Dezembro de 2005, e hoje dele fazem parte 73 famílias, distribuídas ao longo de uma área de aproximadamente 105 hectares.

As famílias se organizam através da formação de núcleos - Che Guevara, Olga Benário, Terra Prometida, Recanto Feliz, Solo Sagrado, Margarida Alves e Eldorado - além de disporem de um espaço destinado a atividades coletivas, que corresponde à área de uso comum do assentamento, local onde acontecem as mais diversas atividades, como oficinas, seminários, reuniões, místicas, festas, cerimônias religiosas etc.

O assentamento é formado por famílias, em sua maioria de origem urbana, que viveram muitos anos essencialmente na periferia de cidades próximas como Limeira, Sumaré e Campinas, e a área do assentamento está inserida em uma região tradicional de latifúndios monocultores de cana-de-açúcar.

\section{Objetivos}

Este projeto tem como finalidade central concorrer para a capacitação dos assentados no que concerne à otimização dos sistemas produtivos, estabelecimento das famílias e do coletivo, numa perspectiva de gestão participativa, que possibilite a resolução dos conflitos que permeiam a lida da comunidade, e possam fornecer subsídios à elaboração de um programa de capacitação e implantação de assentamentos, no âmbito de políticas públicas. 
O assentamento, cujo nome homenageia o grande geógrafo Milton Santos, tem três grandes peculiaridades que representam um grande desafio: é composto por muitas famílias de origem urbana, está localizado em uma região de latifúndios monocultores de cana-de-açúcar e está muito distante das áreas urbanas dos municípios a que estão afetos. Estas peculiaridades são um desafio na medida em que os assentados de reforma agrária, para se consolidarem na terra, têm que lidar com as formas de subordinação de sua renda ao capital. Isto significa que a viabilidade da reforma agrária depende da maneira como estes grupos camponeses se organizam para o atendimento das demandas emergentes, de alimentação, habitação, manejo do solo, produção e comercialização. Neste sentido, é fundamental estender a estes assentados as práticas agrícolas camponesas e as formas tradicionais/culturais para modificar suas trajetórias de vida marcadas fortemente por influências de periferia urbana.

Assim, para se colocar em prática esse resgate, faz-se necessário a realização de atividades de vivência que os façam suscitar e trazer à tona os traços tradicionais e culturais.

Cabe ressaltar que de acordo com a Resolução CONAMA 387, o Licenciamento Ambiental para projetos da reforma agrária requer a elaboração de um diagnóstico ambiental e um projeto de restauração e adequação ambiental que se enquadre no Programa de Desenvolvimento Sustentável (PDS).

A elaboração desses produtos, de caráter multidisciplinar, o que os torna extremamente onerosos, não é assumida pelo Estado, seja através de apoio técnico, seja através de linha de crédito. Por outro lado, é fundamental que os agricultores se apropriem dos conhecimentos contidos nesses relatórios para que possam atuar como sujeitos no planejamento e produção deste novo espaço.

A participação de alunos de graduação neste projeto permite que os mesmos desenvolvam além das habilidades inerentes à pesquisa científica, aquelas relacionadas à elaboração de diagnósticos e prognósticos que concernem ao planejamento, colaborando com a efetiva implantação do projeto de assentamento.

\section{Conexão do Projeto de Extensão com o Projeto Pedagógico do Curso de Geografia}

O projeto em curso está em consonância com o Projeto Pedagógico do curso de Geografia da Universidade de São Paulo.

No mencionado Projeto Pedagógico consta a seguinte ponderação a respeito da formação de nossos alunos de graduação:

Não se pode mais ignorar o reconhecimento da constituição de um espaço planetário complexo, sobretudo diante das profundas e sérias mudanças globais ambientais que já afetaram ou que põe em risco a vida no planeta. Para a geografia torna-se necessário refletir sobre os modos como esses processos mundiais se constituem no espaço brasileiro, pois o geógrafo deve contribuir para, através de seu trabalho, aprofundar a análise e a compreensão da realidade no que ela tem de global e de específico. Pensar o homem e seu mundo, tal como se reproduz na cotidianidade de suas relações sociais. (UNIVERSIDADE DE SÃO PAULO, DEPTO DE GEOGRAFIA, 2004, p.5)

Neste sentido, realizar uma pesquisa a respeito de assentamentos agrários significa compreender o processo de reprodução do capital no mundo atual e, especificamente, a sua contraditoriedade através da territorialização do trabalho camponês. Desta maneira, o trabalho de campo, prática clássica do fazer geográfico, tem lugar central no processo de desvendamento da realidade em uma perspectiva eminentemente geográfica. Portanto, o desvendamento da trajetória de assentamentos de reforma agrária pressupõe a realização da pesquisa empírica como ferramenta fundamental para pensar o homem e seu mundo, tal como se reproduz na cotidianidade de suas relações sociais.

Desta forma, em nossa concepção, conforme explicitada em nosso Projeto 
Pedagógico, a pesquisa tem lugar central na formação de nosso graduando:

\begin{abstract}
A Universidade é o locus privilegiado da produção do conhecimento, que se constrói, basicamente, no cotidiano da pesquisa, enquanto produção crítica e original, sem a qual não há ensino comprometido com a formação do cidadão. É preciso reforçar que o conhecimento só pode ser produzido através do comportamento crítico e do exercício de liberdade e de existência do pleno direito à diferença. (UNIVERSIDADE DE SÃO PAULO, DEPTO DE GEOGRAFIA, 2004, p.5)
\end{abstract}

Neste sentido, buscamos na formação de nossos alunos e, particularmente no desenvolvimento deste projeto, "desenvolver as habilidades do pesquisar e do questionar o conhecimento".

Para realizar uma pesquisa acerca das práticas agrícolas de assentados de reforma agrária, através deste projeto, os alunospesquisadores estão tendo a oportunidade de aprender e aplicar as técnicas necessárias para o desenvolvimento da pesquisa. Dentre estas técnicas apresentam-se: a observação de campo, a realização de entrevistas/questionários com as famílias camponesas, a elaboração de cartas (mapas) específicas que orientem o uso e ocupação do solo, o diagnóstico do meio físico e socioeconômico, a avaliação da potencialidade de comercialização dos produtos cultivados, a sistematização dos dados e informações coletados, o desenvolvimento de projetos de saneamento, habitação, produção agrícola, numa experiência de gestão participativa, que seguramente concorrerá para o enriquecimento de sua formação acadêmica e afloramento de sua cidadania.

\section{Fundamentação contextualização \\ teórica \\ e}

Os sucessivos conflitos e a emergência de movimentos sociais envolvidos com a luta pela terra têm marcado o Brasil principalmente nas últimas duas décadas, gerando uma alteração de sua configuração territorial. É necessário, portanto, que tenhamos as ferramentas teóricas adequadas para o desvendamento da formação territorial do Brasil, em especial no que se refere à compreensão da questão agrária.

Estas ferramentas teóricas dizem respeito ao entendimento dos processos históricos relacionados à propriedade da terra no Brasil e de conceitos que são fundamentais para a compreensão do campo brasileiro na atualidade, especialmente neste momento de mundialização do capital.

Algumas ideias e conceitos têm sido importados pela geografia agrária, de autores da economia ou da sociologia, sem que uma reflexão aprofundada sobre o significado dos mesmos tenha sido feita.

Entre estas ideias tem tomado força a "de novo rural", segundo a qual o campo brasileiro tem se tornado mais moderno e cada vez menos agrícola e mais "plural". Os camponeses, nesta concepção, vão deixando de sê-lo, para se tornarem agricultores familiares (uma espécie de pequenos empresários do campo) ou simplesmente assalariados.

Há três grandes perigos nessa concepção: o primeiro é o de não enxergar a peculiaridade do campesinato enquanto classe social e, portanto, negligenciar a especificidade de sua ação e trajetória. O segundo é que neste caminho de entendimento não há possibilidade de compreender a ação dos movimentos sociais no campo que têm como bandeira a execução de uma reforma agrária ampla. O terceiro, particularmente do ponto de vista da geografia, é que não se consegue abarcar a transformação do território em toda a sua contraditoriedade, determinada pelo modo de produção capitalista.

Sabemos que o capital não se reproduz de maneira única, mas que, ao contrário, seu processo de reprodução é contraditório e esta contraditoriedade marca o território brasileiro e, sobretudo, o campo, de uma maneira muito específica. Temos lado a lado a agricultura camponesa e a agricultura capitalista desenvolvendo-se. Temos um movimento camponês extremamente atuante e de proporção 
nacional que vem buscando a realização de uma reforma agrária de forma ampla e massiva e que, no limite, tem questionado a lógica da apropriação da terra no Brasil e tem provocado alterações territoriais, sociais, econômicas e políticas, no campo brasileiro.

Ocorre que as últimas ocupações de terra e marchas dos movimentos sociais têm posto a nu o poder do latifúndio no Brasil.

O Brasil não só foi um dos países com pior concentração fundiária do mundo, como ainda é. Oliveira (2003) nos mostra que temos as pequenas propriedades, com menos de 100 hectares - que são $84 \%$ dos estabelecimentos agrícolas - ocupando apenas $17 \%$ da área total. Em contrapartida, os maiores estabelecimentos - com mais de 1000 hectares - que correspondem a apenas $2,4 \%$ do número total de estabelecimentos - ocupam $50 \%$ da área. Oliveira (2003) nos mostra também que se somarmos a área das 27 maiores propriedades rurais no Brasil, temos uma área equivalente ao estado de São Paulo inteiro.

O mecanismo do latifúndio na atualidade - que espantosamente é improdutivo ou "reprodutor" daquilo que poderíamos chamar de monocultura nefasta (excludente de pessoas e devastador do meio ambiente) - se apresenta exatamente da mesma maneira como já havia se apresentado em outros momentos de nossa história quando da atuação de outros movimentos sociais. O que nos permite jocosamente dizer que ao contrário de estarmos diante de um novo rural, estamos na verdade, diante de nosso "Velho Rural".

É isso que os movimentos sociais, em especial o MST, estão trazendo para a ordem do dia. Estes movimentos estão colocando em questão a incoerência de um país com $60 \%$ das terras improdutivas e 30 milhões de miseráveis.

Neste sentido, estamos diante da construção de uma reforma agrária, perpetrada a partir da ação de classe do campesinato, que tem trazido para a realidade brasileira perspectivas antes impensadas. Por um lado, verifica-se o avanço da territorialização camponesa em si a qual, além da importância econômica, tem significado, para as famílias assentadas, a possibilidade de um salto na condição de vida (sob diferentes aspectos). De outro, tem-se a participação crescente de famílias de origem urbana no movimento social de luta pela terra. Uma parte significativa dos atuais acampamentos tem sido composta por famílias/ pessoas de origem urbana. Este caráter é, de alguma forma, inovador na trajetória da luta pela terra e, também, vai na contramão da trajetória migratória que grassa o país há décadas.

Entretanto, tem sido um desafio para os projetos de reforma agrária a contínua luta contra a subordinação da renda camponesa ao capital. Esta subordinação se dá de três formas: ao capital industrial, ao capital financeiro e ao capital comercial. (Bombardi, 2005)

É fundamental, portanto, quando se trata de assentamentos camponeses, uma prática agrícola que busque superar as formas clássicas de subordinação da renda ao capital. Neste sentido, esta pesquisa visa contribuir com a consolidação de formas de produção adequadas não só ao ambiente em que estão inseridas, como também, ao mercado consumidor presente no entorno do assentamento.

Neste sentido, este projeto visa - além de desvendar a territorialidade originada pelas práticas agrícolas já consolidadas - contribuir com a introdução de práticas agrícolas adequadas não só ao ambiente em que estão inseridas, como também, ao mercado consumidor próximo ao assentamento.

As famílias, em contato com o Movimento Social (MST - Movimento dos Trabalhadores Rurais Sem Terra), passaram a acalentar a possibilidade de serem assentadas e reviverem a situação outrora perdida: a da vida camponesa.

Acompanhadas pelo grupo que ora desenvolve este trabalho têm encontrado formas diversas de produzir, desenvolvendo, por exemplo, uma agricultura consorciada em que são empregados diferentes tipos de leguminosas e tubérculos, olericultura e fruticultura orgânicas, e criação de pequenos animais numa escala que 
ainda mal pode ser classificada como de subsistência.

Entretanto, todos os desafios comuns à agricultura camponesa também se lhes impõe, na medida em que buscam encontrar formas de evitar a subordinação de sua renda. Neste caso, aliás, estamos diante da territorialidade camponesa imersa no "mar de cana" fruto da territorialização do capital (Thomaz Jr, 1988).

Desprovidos dos elementos da cultura campesina que instrumentalizariam a produção de um espaço harmônico de vivência e produção, esses assentados têm que lidar com responsabilidades que não conseguem compreender sem contar com políticas públicas que lhes dêem o devido suporte. A Resolução CONAMA 387, que dispõe sobre o licenciamento ambiental nos projetos de Reforma Agrária, atribui aos assentados o ônus e a responsabilidade pela elaboração do diagnóstico ambiental e da elaboração de projeto de adequação e restauração ambiental, que se enquadre no Programa de Desenvolvimento Sustentável.

A elaboração destes produtos, de caráter multidisciplinar, o que os torna extremamente onerosos, não é assumida pelo Estado, seja através da disponibilização de assessoria técnica, seja através de linhas de crédito.

As condições nas quais se insere este projeto de extensão surgem de uma constatação a respeito da realidade local de avaliação bastante negativa, quando se leva em consideração a qualidade da assistência oferecida pelo INCRA órgão que, em teoria, é o responsável pelo desenvolvimento e pela assessoria daquele conjunto. Considerando-se que o grupo de indivíduos que faz parte da Comuna da Terra Milton Santos é predominantemente de origem urbana, e - ainda mais importante - de passado de pouca estabilidade financeira e de localização, nota-se uma clara aversão, por parte dos assentados, de qualquer tipo de projeto coletivo. Além disso, ao longo dos vários contatos que já estabelecemos com eles, e com a criação de uma rede de confiança entre estes dois agentes (universidade e Comuna), de seus anseios e desejos, de suas aspirações para o local e da forma como têm se apropriado deste espaço, percebe-se que os hábitos e a cultura próprias da vida urbana estão de tal modo neles arraigados que o dito processo de recampenização de uma população que pode vir a ser o novo sujeito da reforma agrária não é um processo natural, mas algo a ser construído coletivamente.

Mais que hábitos da vida urbana, notamse os hábitos e a cultura própria de uma realidade urbana marcada pela violência, pelo medo e pela manutenção das condições mínimas de sobrevivência cotidiana: o passado de parte das pessoas que aí passarão a cultivar suas vidas muitas vezes é o daquele indivíduo que cresceu na favela ou esteve em situação de rua, daquele sujeito cuja relação com o Estado e com o poder constituído é intermediado pelo uso da repressão policial, da pessoa que sempre aprendeu a desconfiar de todos aqueles com quem estabelece qualquer tipo de relação. Não apresenta os traços de uma cultura popular dita "vernacular" - as manifestações culturais com as quais lida, diferentes daquelas das do homem do campo, são tomadas a partir da agenda imposta pelas mídias de massa. A relação que estabeleceu com a cidade e com o urbano muitas vezes foi a de associar tais ideias às da favela, da segregação, da violência a que o status quo submete as classes populares - submissão a um sistema de transporte coletivo de massas sufocante, obsoleto e saturado, submissão a um modelo marcado pela negação de direitos sociais e pela inexistência de um estado de bem-estar social instituído minimamente a oferecer condições de reprodução da força de trabalho, negação do acesso à moradia em áreas dotadas de infraestrutura, enfim, negação geral do "direito à cidade". Um duplo sentimento passa a ser nutrido: de um lado, o sentimento antiurbano, uma tentativa instintiva de negar aquela negação pela associação da cidade com tudo o que foi responsável pela violência cotidiana que naturalizou-se em suas existências. De outro lado, um sentimento de admiração pelo espetáculo urbano midiático a que não têm acesso. 
O recurso à autoconstrução, as redes de trocas informais, a instabilidade de renda oriunda das atividades informais de trabalho são todas estratégias de sobrevivência - provisórias em princípio - que se naturalizam como algo próprio do dia-a-dia na cidade, tornando-se algo permanente.

Do ponto de vista específico do trabalho com a cultura arquitetônica e construtiva do assentamento, cabe destacar alguns aspectos das anotações dos parágrafos anteriores.

Em primeiro lugar, tratamos com um grupo social que não possui cultura construtiva vernácula. Embora sejam poucos os estudos a respeito da arquitetura popular brasileira, da arquitetura do cotidiano, da arquitetura das pessoas simples e das práticas e das técnicas construtivas que são passadas e ensinadas em situações de oralidade e informalidade, todos eles costumam lidar com populações distantes dos grandes centros urbanos (fala-se ora do trabalho das populações caiçaras, ora do trabalho das populações rurais, etc). Não se pode falar em artesanato ou em tradições construtivas passadas de boca em boca nas periferias urbanas, por mais que o bloco cerâmico furado ("tijolo baiano", segundo o linguajar vulgar no qual se introjetaram os vários preconceitos a respeito de tal população), quando ele ainda era hegemônico, ou o bloco de cimento (hoje mais comuns na construção das favelas) sejam elementos construtivos já incorporados a um certo léxico construtivo popular.

Não se trata de artesanato tampouco de arquitetura vernácula. Trata-se de exploração, pura e simplesmente.

No fim da década de 1960, Ferro (2005, p. 62-63) produziu aquela que seria a primeira análise relativamente aprofundada a respeito da produção da habitação no Brasil. Alegando que,

[...]a técnica utilizada, mais do que aprendida, é vista, vivida, absorvida por contínua vizinhança. Faz parte do conhecimento popular quase espontâneo, que todos herdam, simples prática compatível com nenhuma especialização [...] Desprovido de qualquer meio de produção, é operário, recolhe a experiência feita sem equipamento pouco mais complexo. Devendo contar somente com ele próprio, sem qualquer folga para aprendizado, reencontra, cada vez mais, a mesma técnica pré-histórica. [grifos nossos]

Não se trata da apropriação de um conhecimento tradicional, mas do uso das ferramentas e das possibilidades mais apropriadas às exigências do momento. Em um país cujo capitalismo não serve para atender às condições de reprodução das classes populares, não existe produção de massas de habitação industrializada, racionalizada, estandartizada, como se vêem nos grandes conjuntos do pósGuerra europeu - e tampouco é possível àquelas classes produzir suas condições de sobrevivência por meio de técnicas de construção tradicionais um conhecimento que por elas foi perdido ao longo do processo de urbanização. Seja a construção de tijolos cultivada pelos mestres populares imigrantes, que marcou os bairros operários do início do século $X X$, sejam os vários tipos de construção com terra (taipa de sopapo, taipa de pilão, taipa portuguesa, etc) que se desenvolveram desde a Colonização até o período, no caso de São Paulo, da cidade de alvenaria.

"Bater uma laje" (com o uso de um sistema semi-industrializado de elementos cerâmicos pré-moldados ora produzidos em fabriquetas sem certificação, ora produzidos em grandes empresas, mas cuja circulação é tão eficiente que pode ser encontrado em qualquer loja de materiais de construção em todo o país); "levantar uma parede" (com blocos que não lembram minimamente os antigos tijolos dos artesãos que produziram a cidade do café, mas novamente produtos precários, de tecnologia mambembe e produzidos ora em olarias de esquina, ora em grandes indústrias da construção); esquadrias de chapa dobrada ou de alumínio anodizado, semi-industrializadas (sempre arqueadas, para lembrar construções artesanais, apesar da evidente origem de chãode-fábrica); os famigerados balaústres (mais uma vez, elementos baseados em formas artesanais mas produzidos com cimento e argamassa em 
fabriquetas por meio de linhas de montagem e moldes de origem industrial), são todos elementos deste léxico construtivo que não chegam a constituir de fato uma cultura construtiva popular, mas uma estratégia de sobrevivência apropriada pelas classes de menor renda e que dá à indústria da construção, todos os anos, os lucros que conhecemos.

O resultado desta apropriação como estratégia de sobrevivência, que leva a uma naturalização das possibilidades construtivas como únicas reais, é o da sua aceitação cega em qualquer situação e o da negação imediata de quaisquer outras alternativas.

Em segundo lugar, é preciso destacar como o caráter de informalidade gerado pelas formas como os loteamentos populares urbanos, as favelas, as acomodações das populações em situação de rua, entre outros, passa a ser a grande referência deste grupo social com relação ao tema "morar junto". Quando apresentados à ideia de promover agrovilas na Comuna, a reação geral foi de aversão e busca de uma situação de isolamento e reprodução da lógica do lote urbano, no qual as construções sempre tendem a ficar implantadas sozinhas e afastadas dos seus limites - sinal de riqueza e status na cidade, pois em lotes pequenos os recuos são sempre evitados por questão de economia.

Desta forma, que ideia "casa" têm estas famílias, estes indivíduos, este sujeito coletivo? Em muitos sentidos, os anseios, os desejos, os sonhos de realização da "casa própria" na Comuna em pouco diferem da imagem de residência construída e veiculada pelo mercado imobiliário dos grandes centros urbanos. Os usos da casa são estanques e nada flexíveis - uma cozinha é uma cozinha, uma sala é uma sala, um quarto é um quarto. A organização interna da casa que desejam é similar a das casas urbanas, mas nem sempre é a mais adequada à casa rural.

Neste sentido, qual o papel a ser cumprido pelos equipamentos coletivos da Comuna? Se o loteamento, como fato consumado, reflete um desejo de um tecido mais suburbano que rural, com lotes isolados e distantes ao invés de projetos de agrovilas, como assegurar que tais equipamentos possuam um papel central na vida cotidiana das pessoas - e mais que isto, qual o efetivo papel político que eles terão? Lembrando Lefèbvre (2008, p.49):

Ora, a tese da "socialização da sociedade", interpretação evolucionista e reformista, assume outro sentido se observarmos que essas palavras designam mal, incompletamente - a urbanização da sociedade. A multiplicação e a complexificação das trocas no sentido amplo da palavra não podem continuar sem que existam locais e momentos privilegiados, sem que esses lugares e momentos de encontro se libertem das coações do mercado, sem que a lei do valor de troca seja dominada, sem que se modifiquem as relações que condicionam o lucro. Até esse momento, a cultura se dissolve, tornando-se objeto de consumo, ocasião para o lucro, produção para o mercado; o "cultural" dissimula mais de uma armadilha.

Não poderia o projeto da habitação e de equipamentos coletivos como a cozinha comunitária tornar-se um instrumento de discussão a respeito da aculturação destas pessoas no campo, de uma outra cultura que não aquela mediada pelo capital, em um processo contínuo em que ao mesmo tempo em que se aprimoram práticas, técnicas e culturas construtivas novas e recuperadas também se aprimore esta nova cultura que não tem no valor de troca o elemento fundamental?

As precárias condições de assistência técnica oferecidas pelo INCRA (que não exige a apresentação de projetos para as casas, tampouco exige ou oferece acompanhamento técnico para a execução das mesmas) aos assentados da Comuna da Terra Milton Santos acabam por fornecer possibilidades de trabalho estimulantes segundo uma perspectiva de construção de uma articulação entre universidade e movimento social de dupla ordem: de um lado, o da formação política geral, de outro lado, o da formação profissional segundo o horizonte daquela realidade social. 


\section{A metodologia e a prática}

Procurou-se ao longo desses dois anos estabelecer uma condição próxima a de "Pesquisador visitante" através de uma frequência elevada de trabalhos de campo, quinzenais, e de estadias semanais dos alunos envolvidos: duas coletivas - com dois alunos hospedados em cada residência, e duas individuais - alunos envolvidos em projetos específicos.

Os trabalhos deram-se, principalmente, sob a forma de oficinas em que a equipe se propunha a intermediar a apreensão dos conhecimentos pelos assentados, tanto relativas à organização dos sistemas produtivos, quanto aquelas relacionadas à legislação que regula estas atividades. Nesse processo procurou-se introduzir a prática da gestão participativa, como forma de organização e resolução de conflitos.

Sempre que possível, essas oficinas foram realizadas com o coletivo. Em casos específicos, como o da caracterização da cobertura pedológica, da localização das nascentes ou de práticas agrícolas, utilizou-se da abordagem do "multiplicador", através da qual os assentados que demonstravam maior interesse participavam da oficina e se encarregavam de transmitir o conhecimento adquirido para os outros assentados.

Visando a contextualização dos resultados obtidos, está sendo realizado um levantamento socioeconômico dos assentados, bem como da estrutura de comercialização e abastecimento nos municípios afetos.

\section{Caracterização socioeconômica}

Além de fornecer uma base para a contextualização dos outros produtos pretendidos, a caracterização socioeconômica propõe subsídios indispensáveis para a construção de uma proposta de Gestão Participativa ao evidenciar as diferenças interpessoais geradoras de conflitos.

Ela está sendo implementada através de entrevistas com questionários não estruturados, realizadas por duplas de alunos. Os resultados destas entrevistas serão posteriormente tabulados, submetidos à análises estatísticas. A interpretação destes resultados à luz daqueles obtidos no levantamento dos hábitos alimentares, poderá subsidiar um programa de segurança alimentar que venha a nortear o planejamento dos sistemas produtivos

\section{Reconhecimento do Meio Físico}

A partir de uma base topográfica 1:10.000, fotos aéreas e georreferenciamento, foram realizadas oficinas para mapeamento de uso e ocupação do solo e delimitação das unidades de solo, que permitiram a construção de uma maquete, utilizada como um instrumento tanto no processo de leitura da paisagem, como de planejamento das intervenções necessárias ou pretendidas.

No final de julho de 2008 os alunos concluíram a maquete, "colorindo" as manchas de solo com amostras do próprio solo coletadas no assentamento Milton Santos. O objetivo era justamente oferecer de forma "palpável" elementos para que os assentados pudessem reconhecer: como o solo se apresenta qualitativamente no assentamento; como é a atual divisão dos lotes; como é o tamanho de cada lote em relação aos demais; como a divisão dos lotes está em relação à qualidade do solo em cada parcela; qual seria o domínio natural da mata ciliar e qual a área a que ela se encontra circunscrita, em quais áreas o solo se encontra mais degradado, entre outros elementos, conforme se observa na fotografia apresentada a seguir.

No dia 29/07/2008 o Grupo de PesquisaExtensão foi ao Assentamento Milton Santos apresentar a maquete, realizando a seguinte oficina:

1. A primeira parte da atividade se caracterizou como um momento de interpretação livre, onde os participantes puderam expressar suas percepções sobre a realidade ali representada. Pode-se constatar respostas sensitivas interessantes, como reconhecimento, 
surpresa, limites de compreensão, o que pode servir de subsídio para a continuidade da atividade (e seus limites), podendo ser reconduzida a partir do que se vive no momento. Isso não implicaria desvio do que se propõem, mas no enriquecimento, que é próprio de um processo orgânico.

2. Em um segundo momento, com o propósito de uma contextualização espacial da maquete, foi proposta a colocação da maquete no chão de terra (ao lado do barracão), e com a colaboração de todos riscamos no próprio solo as cidades vizinhas como Cosmópolis e Limeira, etc. $O$ fato de se trabalhar, nesta fase, com posições geográficas imprecisas não deve ser motivo de uma suposta confusão no entendimento e nem representar a falta de rigor, sendo que pode, inclusive, servir como introdução sobre a questão de escala. Além disso, coloca a possibilidade de discutir duas aproximações da realidade: uma ilustrativa (o desenho livre na terra) e a outra em escala, que segue o rigor científico.

3. Nesse momento pôde-se fazer a ligação com a leitura mais detalhada da maquete. Cada pessoa ou núcleo (trabalho em grupo) - procurou localizar seus respectivos lotes.

4. No momento seguinte, procurou-se estimular proposições sobre quais outras possibilidades de exploração desse material podem existir:

- Observação de solos mais, ou menos produtivos;

- Região de mata, reflorestamento;

- Abundância/escassez de água;

- Águas mais ou menos sujas;

- Pontuar as nascentes;

- Estrutura da rede elétrica e da de distribuição de água;

- Discutir o esgoto;

- Discutir o que é o assentamento hoje, partindo do pressuposto de que aquela é uma representação congelada da história;
- Discutir o que pode ser o assentamento, tendo como possibilidade a construção de uma segunda, terceira... maquetes que representem novas configurações de lotes, espaços coletivos, captações de água, de energia, áreas de plantio, etc;

- Apresentação da comuna para visitantes, entre outras.

A oficina teve um resultado bastante positivo já que dela participaram pelo menos um representante de cada núcleo do assentamento e, também, o agrônomo do Incra que dá assistência ao assentamento. Na oficina os assentados vieram até a maquete para localizar seu próprio lote, fizeram observações sobre o solo, puderam compreender o sentido da "escala" na maquete (ocasião em que muitos se surpreenderam ao descobrir que a representação correspondia às distâncias reais), localizaram os lotes dos vizinhos, observaram a cor e a textura do solo e discutiram conosco todos estes elementos.

No atual estágio de nosso trabalho, entendemos que a maquete possa ser um importante instrumento para o Planejamento do Assentamento em conjunto com o técnico do INCRA.

Segundo Paulo Freire (1977, p. 44):

No momento em que um assistente social, por exemplo, se reconhece como "o agente da mudança", dificilmente perceberá essa obviedade: que, se seu empenho é realmente educativo libertador, os homens com quem trabalha não podem ser objetos de sua ação. São, ao contrário, tão agentes da mudança quanto ele. A não ser assim, ao vivenciar o sentido da frase, não fará outra coisa se não conduzir, manipular, domesticar.

Nesta perspectiva, entendemos que nosso papel é construir elementos - em conjunto com os assentados - definidos a partir das necessidades apontadas e percebidas por eles próprios, no processo complexo e desafiador de construção de suas vidas no assentamento. 


\section{Adequação Ambiental}

Tem sido realizadas oficinas relacionadas à qualidade e disponibilidade de água, restauração funcional da mata ciliar e a restauração da cobertura pedológica através da implementação de sistemas orgânicos e agroflorestais de cultivo.

A questão sobre disponibilidade e qualidade da água tem se configurado como a maior preocupação dos assentados. A água que abastece o assentamento se origina em parte do córrego Jacutinga e em parte de um poço artesiano instalado pelo DPRM. A vazão somada destas duas fontes, nos períodos secos, mal dá para atender o consumo humano e dessedentação de animais, inviabilizando a irrigação das hortaliças, principal produto do assentamento.

Foram também realizadas várias oficinas para a discussão de um projeto de saneamento, que permitisse o aproveitamento do lodo para a produção de compostagem a ser utilizada nos sistemas de cultivo e do gás para uso doméstico.

Os assentados demonstram uma grande dificuldade em assimilar a responsabilidade quanto ao tratamento de esgotos, uma vez que em sua vida urbana pregressa, isto era de responsabilidade do Estado.

\section{Cultura construtiva}

Foram propostas a condução de uma série de oficinas e experiências de arquitetura de terra (taipa apiloada especificamente) como forma de discutir com a população uma outra cultura construtiva que não aquela mediada pelos elementos semi-industrializados que marcam a paisagem urbana das periferias das grandes metrópoles.

Sugeriu-se também o uso da taipa de pilão como sistema construtivo das residências unifamiliares como forma de intermediar um processo de discussão e problematização da casa daquelas famílias: da estética às relações de produção e trabalho, a escolha do material de construção não é uma decisão ingênua ou apolítica, pois interfere diretamente no circuito de produção de circulação dos materiais e no trabalho das pessoas envolvidas. O uso da taipa - segundo uma perspectiva contemporânea, com incremento de tecnologia e de pesquisas tecnológicas realizadas pela universidade, se coloca como potencialidade de ressignificação da técnica construtiva e de negação daquelas técnicas que tinham o papel de ser estratégia de sobrevivência nas periferias urbanas. Não se escolhe a taipa por sua característica de tradição - ainda que seja "tradicional", pois seria uma tradição alheia àquelas pessoas - mas pelas possibilidades culturais, políticas e econômicas que ela sugere nestas condições.

Justamente devido à falta de compromisso por parte do INCRA em promover assistência técnica aos assentados - e ressaltando que não é nosso objetivo cumprir esta lacuna, mas de problematizá-la junto à Comuna em suas dimensões culturais (arquitetura, estética, construção, etc) e políticas - revela-se também a inexistência de um empecilho comum à realização de um processo autogestionário de projeto e construção das residências e dos equipamentos coletivos.

A promoção de um processo de construção das casas que seja resultado de um processo de projeto democrático e com envolvimento da população envolvida é um pressuposto para a discussão dos temas levantados logo acima. Neste sentido, a promoção de um projeto arquitetônico que não seja imposto à população, mas que seja resultado de um contínuo diálogo entre público leigo (usuários) e os "técnicos" (estudantes, comunidade universitária) leva a uma situação em que o conceito de "autoria" individual seja questionado - elemento fundamental em qualquer discussão sobre a interface entre cultura dita popular e cultura dita erudita. O foco deixa de estar no projeto - nos desenhos, na configuração formal, na estética acabada e final - e passa a estar nas interfaces e na cultura construtiva que estamos articulando - na estética do contínuo fazer, em algo que não se revela imposto em sua forma final, mas uma obra aberta e que muda segundo as condições 
individuais de cada família, mas que pode revelar uma paisagem e um espaço íntegro e coerente.

$$
\text { Segundo Arantes (2002, p.209): }
$$

[...]Se os arquitetos estiverem motivados a construir obras com invenção e não apenas reproduzir com correção técnica a autoconstrução, quais argumentos devem utilizar, por exemplo, para rechaçar os balaústres ou as janelas arqueadas coloniais? Para isso o arquiteto não pode apenas lançar mão de sua razão técnica, afirmando, por exemplo que são elementos construtivos antieconômicos, pois estaria assim impedindo o diálogo franco e restituindo sua 'autoridade' inquestionável de técnico de nível superior. Se é preciso criar uma cultura arquitetônica comum entre arquitetos e mutirantes, ela deve ser francamente debatida e experimentada até consolidar um novo imaginário do que seja o habitat popular numa grande cidade. [grifos do autor].

A relação entre a construção de um trabalho de extensão que une promoção da autogestão com discussão e construção coletiva de uma cultura arquitetônica popular alternativa à das periferias urbanas e a articulação que se cria entre universidade e movimento social revela enfim que existe a potencialidade de se vislumbrar alternativas de mudança.

\section{Considerações finais}

O contingente de alunos de graduação e pós-graduação que foi se agregando ao projeto, atesta a existência de uma demanda no corpo discente por este tipo de vivência. Os resultados verificados até o presente evidenciam o quanto este verdadeiro laboratório de campo, montado com a participação de professores de várias unidades da USP, pode contribuir para enriquecer a formação acadêmica de nossos alunos.

Para os docentes envolvidos tem-se o instigante desafio de elaborar projetos de pesquisa que atendam às demandas emergentes dos assentados, tanto quanto dos alunos envolvidos. Neste sentido, além dos projetos de conclusão de curso e dissertação de Mestrado em curso, emergiram do âmago deste trabalho, os projetos:

"Bases Ecológicas e Sociológicas para a construção e o aprimoramento da políticas públicas voltadas à restauração da matas ciliares". Políticas Públicas/ FAPESP ( Ref. Processo:2077/55386-0). Pesquisador Responsável: Prof. Dr. Paulo Yoshio KageyamaProfa. Dra. Sidneide Manfredini ( coordenadora temática).

"Contribuição ao processo de capacitação de agricultores do projeto de reforma agrária no Assentamento Milton Santos - Americana,SP." Projeto de Extensão Universitária encaminhado ao MEC - PROEXT, 2009.

\section{Bibliografia}

ARANTES,P. Arquitetura Nova. São Paulo: Editora 34, 2002.

BOMBARDI, L. M. Campesinato, luta de classe e reforma agrária (A Lei de Revisão Agrária em São Paulo). São Paulo, 2005. Tese (Doutorado em Geografia Humana). Departamento de Geografia, Faculdade de Filosofia, Letras e Ciências, Universidade de São Paulo.
FERRO, S. "A produção da casa no Brasil". In: Arquitetura e trabalho livre. São Paulo: Cosac e Naif, 2005.

FREIRE, P. Extensão ou Comunicação?. São Paulo: Paz e Terra, 1977.

LEFÈBVRE, H. Direito à cidade. São Paulo: Centauro, 2008. 
OLIVEIRA, A.U. "Barbárie e modernidade: as transformações no campo e o agronegócio no Brasil". In: Terra Livre, São Paulo, Ano 19, v.2, no 21. p.113-156. Jul-Dez. 2003.

SALIM, A. Pré-assentamento Comuna da Terra Milton Santos: história de vida, história de luta. Campinas, 2007. (Trabalho de Conclusão de Curso apresentado à Faculdade de Geografia da PUCCampinas, para obtenção do título de Bacharel em Geografia).
THOMAZ JR. A territorialização do monopólio: As agroindústrias canavieiras em Jaboticabal. São Paulo, 1988. Dissertação (Mestrado em Geografia Humana) Departamento de Geografia, FFLCH, USP.

UNIVERSIDADE DE SÃO PAULO. FACULDADE DE FILOSOFIA, LETRAS E CIÊNCIAS HUMANAS. DEPARTAMENTO DE GEOGRAFIA. Plano de Metas Acadêmicas 2004-2008. São Paulo: Departamento de Geografia, 2004. Mimeo.

Trabalho enviado em outubro de 2009

Trabalho aceito em novembro de 2009 
